\title{
FATIGUE PROPERTIES OF TI6AI4V PREPARED BY SELECTIVE LASER MELTING
}

\author{
${ }^{1}$ Monika LOSERTOVÁ, ${ }^{1}$ Vojtěch KUBEŠ, ${ }^{2}$ Zdeněk ČEJKA, jr., ${ }^{3}$ František FOJTÍK, \\ ${ }^{1}$ Kateřina KONEČNÁ, ${ }^{1}$ Martin KRAUS, ${ }^{1}$ Tomáš ČEGAN \\ ${ }^{1}$ VSB - Technical University of Ostrava, Faculty of Materials Science and Technology, Ostrava, \\ Czech Republic, EU, mlosertova@vsb.cz \\ ${ }^{2}$ ProSpon spol. s r.o., Kladno, Czech Republic, EU \\ ${ }^{3}$ VSB - Technical University of Ostrava, Faculty of Mechanical Engineering, Ostrava, Czech Republic, EU
}

https://doi.org/10.37904/metal.2021.4269

\begin{abstract}
The microstructure and fatigue properties of specimens prepared using the selective laser melting technology were analyzed and compared to specimens produced of Ti6Al4V alloy by a conventional way, it means by the casting and forging. The forged samples were studied in both as-received and annealed + hot isostatic pressed conditions; the selective laser melted samples were tested after annealing + hot isostatic pressing. It was proved that the forged specimens showed better fatigue properties than the selective laser melted samples, according to defects formed during the powder-bed-based additive manufacturing process. Small differences in fatigue life were observed for both heat treatment conditions of the forged samples. Despite certain porosity, the selective laser melted samples showed high endurance limit at stress level of $320 \mathrm{MPa}$. Nevertheless, the limit strength value was lower by $26 \%$ and $36 \%$ comparing forged specimens in as-received and heat treated + hot isostatic pressed conditions, respectively. The microstructure of all tested samples was formed of $\alpha+\beta$ phases depending on heat treatment condition. The differences in fatigue fracture features of the forged or selective laser melted specimens corresponded to the microstructure, defects and porosity presence.
\end{abstract}

Keywords: Selective laser melting, Ti6Al4V, fatigue, hot isostatic pressing, stress relief treatment

\section{INTRODUCTION}

There are life situations when a man needs to replace or repair solid tissues or non-functioning joints due to health problems caused by old age, accidents or cancer diagnose. In traumatology, implants of simpler shapes (nails, screws, wires, plates) are mainly used for the tibia, humerus, femur or calcaneus healing. Medium complex shapes and systems as joint replacements for knees, hips, shoulders, or total endoprosthesis are the main implants in orthopaedic surgeons. Simpler implant shapes can be prepared using conventional methods, while more complex geometries or custom-made replacements of specific shapes are either very difficult or impossible to prepare conventionally. These include dental restorations (crowns), cellular structures or cases where an entire bone or even almost the entire rib cage needs to be replaced for an oncology patient. For such situations, a 3D model of the product can be created on the basis of computed tomography, which can be prepared using additive technologies from biocompatible material and then implanted in the patient. This is a fast, efficient, and not too expensive way to significantly preserve quality of life in some cases.

Selective laser melting (SLM) is an additive manufacturing process that can create complex components directly from powdered metal based on CAD files. The production method can form highly complex structures of body implants from certified materials such as $316 \mathrm{~L}$ steel or titanium based alloys with powder grain sizes between $10 \mu \mathrm{m}$ and $60 \mu \mathrm{m}$, where the layer thickness produced is between $20 \mu \mathrm{m}$ and $50 \mu \mathrm{m}$. It is possible to achieve a component accuracy of around $\pm 50 \mu \mathrm{m}$, with production speeds ranging from $5-20 \mathrm{~cm}^{3} / \mathrm{h}$ depending on the size of the machine. The produced parts have a homogeneous structure and almost $100 \%$ density, 
therefore not only the physical but also the mechanical properties of the products match the structure of the castings [1,2].

The quality of the final SLM product depends on the appropriate setting of processing parameters such as scanning speed, laser power, layer thickness, scanning strategy, hatch distance and more. These parameters affect the size of the melt pool, heat-affected region, porosity or amount of unmelted particles and therefore the resulting density or surface roughness, which can be modified by additional remelting of the surface layer. For Ti6Al4V, the influence of the process parameters as well as the heat treatment on the SLM product properties is deeply studied [2-4] and is still of particular interest for biocompatible implants in orthopaedics and traumatology. The SLM process, producing vertically layer by layer, results in the formation of a highly directional microstructure and can lead to certain porosity in the product $[1,5,6]$.

The study of this work is focused on comparing fatigue properties of Ti6Al4V specimens processed by forging or SLM technology. The fatigue behaviour of the material was tested for the specimens after stress relief treatment and hot isostatic pressing.

\section{EXPERIMENTAL}

Two series of Ti6Al4V samples were studied. The first group consisted of ten test specimens, which were prepared from traditionally forged rods, supplied by BIBUS METALS CZ, and are hereafter referred to as forged. The second group included five test specimens, which were prepared by selective laser melting in ProSpon spol. s.r.o. and are hereafter referred to as SLM. The building of the SLM specimens was carried out in vertical orientation (tensile loading axis) with following parameters: laser power $200 \mathrm{~W}$, layer thickness 30 $\mu \mathrm{m}$, scanning island size $5 \times 5 \mathrm{~mm}$ - with an angle of $45^{\circ}$, scanning speed $800-900 \mathrm{~mm} \cdot \mathrm{s}^{-1}$.

Five specimens of both sets were processed by stress relief (SR) treatment and hot isostatic pressing (HIP). The thermal and pressure regime was chosen in accordance with findings in [7,8]. SR treatment was included to remove internal stresses caused by former technologies and was performed for $1 \mathrm{~h}$ at $735^{\circ} \mathrm{C}$ under vacuum (within the range of $0.4-1 \mathrm{kPa}$ ) in a CLASIC furnace, followed by a slow furnace cooling to room temperature in $\mathrm{Ar}$ atmosphere, as seen in Figure 1.

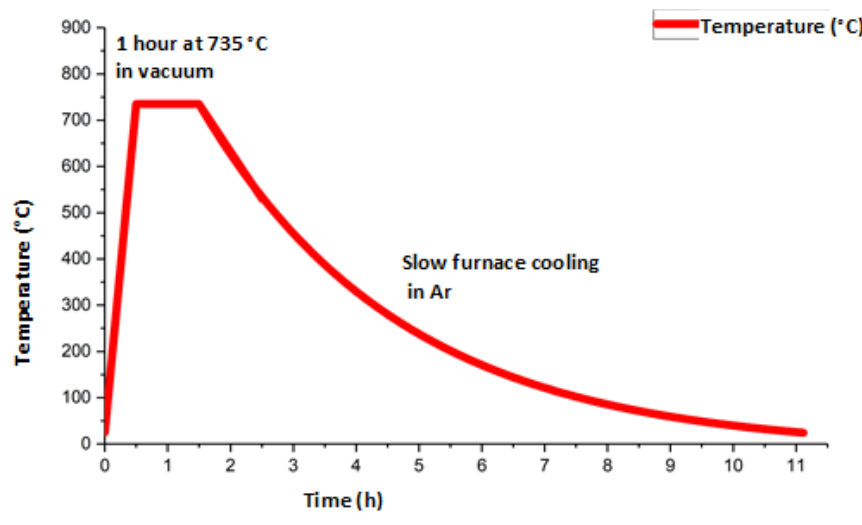

Figure 2 Schematic of the HIP process

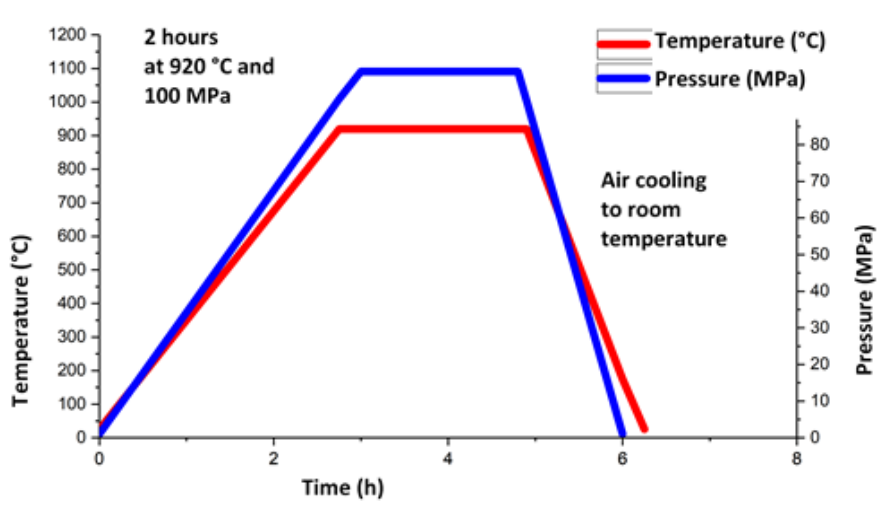

Figure 1 Schematic of stress removal annealing

After annealing the fatigue test specimens were submitted to the HIP process at $920^{\circ} \mathrm{C}$, pressure of $100 \mathrm{MPa}$ in $\mathrm{Ar}$ atmosphere for 2 hours and then air cooled to room temperature. The HIPping was performed in EPSI machine with maximum working pressure of $200 \mathrm{MPa}$, maximum working temperature of $1500{ }^{\circ} \mathrm{C}$ and workspace size of $152 \times 300 \mathrm{~mm}$ in order to reduce the pore content formed during SLM, optimizing the microstructure and thus increasing mechanical properties of material studied. The same process was realized 
for the forged specimens to ensure the same conditions of heat treatment. The schematic diagram of the HIPping performed for experimental samples is presented in Figure 2.

Fatigue behavior of the specimens was studied in alternating tension/compression mode on an INOVA FU-63930-V1 servohydraulic high-speed uniaxial pulsator with loading range $\pm 40 \mathrm{kN}$ and TestControl_FU63 software. The fatigue test frequency was set for $20 \mathrm{~Hz}$ and test termination limit for 200,000 cycles. Before the fatigue test, the surface of all samples was additionally smoothed. Thus, five specimens of $100 \mathrm{~mm}$ overall length, $50 \mathrm{~mm}$ working length and $5.7 \mathrm{~mm}$ working diameter were tested for each studied condition.

Metallographic analysis was performed on the cross cuts prepared from the grip sections of forged and SLM samples after mechanical testing. The samples were ground by means of abrasive papers of grain sizes up to P2500 and polished in electrolyte A3 using a LectroPol-5 Struers electropolisher. Microstructure feature of the specimens was revealed after etching in Kroll's reagent composed of $6 \% \mathrm{HF}, 8 \% \mathrm{HNO}_{3}$ and $86 \%$ deionized water for $10-20$ seconds.

\section{RESULTS AND DISCUSSION}

\subsection{Fatigue testing}

The results of fatigue tests in tension/compression mode for forged and SLM specimens are summarized in Table 1. The values of $\sigma$ in the table represent the maximum reversing stresses at which the fatigue failure will occur. The dependence of the number of cycles to failure $N_{f}$ on reversing stress $\sigma$ is shown below as the S$\mathrm{N}$ curves in Figure 3 and Figure 4. Using Basquin's equation (1) [9] constants $\sigma_{f}^{\prime}$ and $b$ were derived from the measured results (Table 2):

$\sigma=\sigma_{f}^{\prime} \cdot(2 \mathrm{~N})^{b}$

where $\sigma_{f}^{\prime}$ is fatigue strength coefficient, $b$ fatigue strength exponent, number of cycles to failure is given as number of half cycles $2 \mathrm{~N}$.

Table 1 Fatigue test results for forged and SLM specimens in as-received and annealed + HIPped conditions

\begin{tabular}{|c|c|c|c|c|c|c|c|c|}
\hline \multicolumn{2}{|c|}{$\begin{array}{c}\text { Forged specimens } \\
\text { in as-received condition }\end{array}$} & \multicolumn{3}{c|}{$\begin{array}{c}\text { Forged specimens } \\
\text { annealed + HIPped }\end{array}$} & \multicolumn{3}{c|}{$\begin{array}{c}\text { SLM specimens } \\
\text { annealed + HIPped }\end{array}$} \\
\hline $\boldsymbol{\sigma}(\mathrm{MPa})$ & $\boldsymbol{N}_{f}(-)$ & & $\boldsymbol{\sigma}(\mathrm{MPa})$ & $\boldsymbol{N}_{f}(-)$ & & $\boldsymbol{\sigma}(\mathrm{MPa})$ & $\boldsymbol{N}_{f}(-)$ & \\
\hline 520 & 25,912 & broken & 600 & 16,483 & broken & 550 & 3,419 & broken \\
\hline 480 & 61,952 & broken & 550 & 29,084 & broken & 450 & 48,841 & broken \\
\hline 450 & 83,083 & broken & 520 & 64,170 & broken & 380 & 69,185 & broken \\
\hline 450 & 129,822 & broken & 510 & 127,361 & broken & 340 & 170,533 & broken \\
\hline 430 & 200,000 & unbroken & 500 & 200,000 & unbroken & 320 & 200,000 & unbroken \\
\hline
\end{tabular}

Small differences in fatigue life were observed between both heat treatment conditions for the forged samples, as the results in the columns of cycles to failure $N_{f}$ indicate in Table $\mathbf{1}$ and in Figure 3 . It is evident that the highest stress amplitude for unbroken stage and 200,000 life cycles was reached in the case of forged sample in annealed + HIPped condition. Conversely, SLM specimen in annealed + HIPped condition remained unbroken at the lowest value of all reversing stresses. Despite certain porosity, the selective laser melted sample showed high fatigue resistance at loading level of $320 \mathrm{MPa}$ (Table 1, Figure 4). Nevertheless, the endurance limit value was lower by $26 \%$ and $36 \%$ comparing forged specimens in as-received and heat treated + hot isostatic pressed conditions, respectively. 


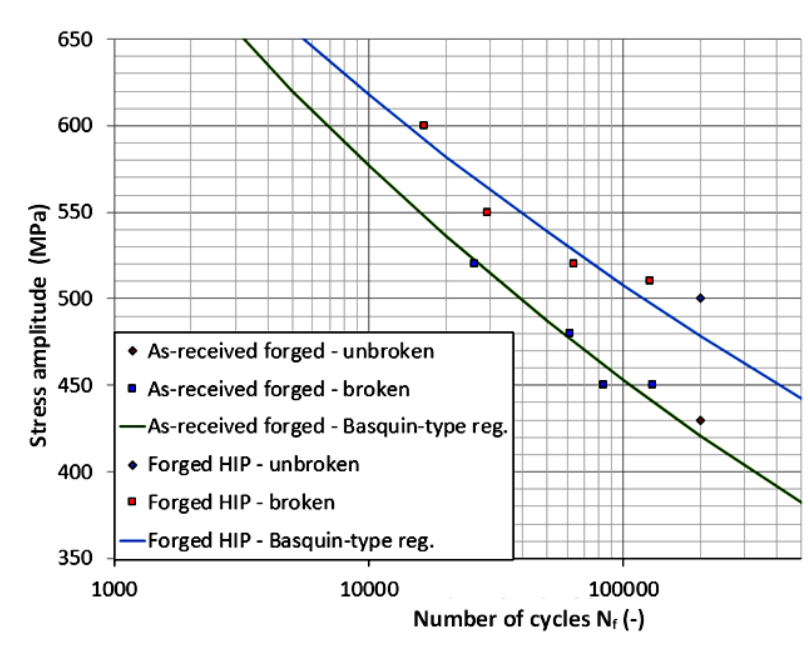

Figure 3 Comparison of S-N curves for forged samples in as-received and annealed + HIPped conditions

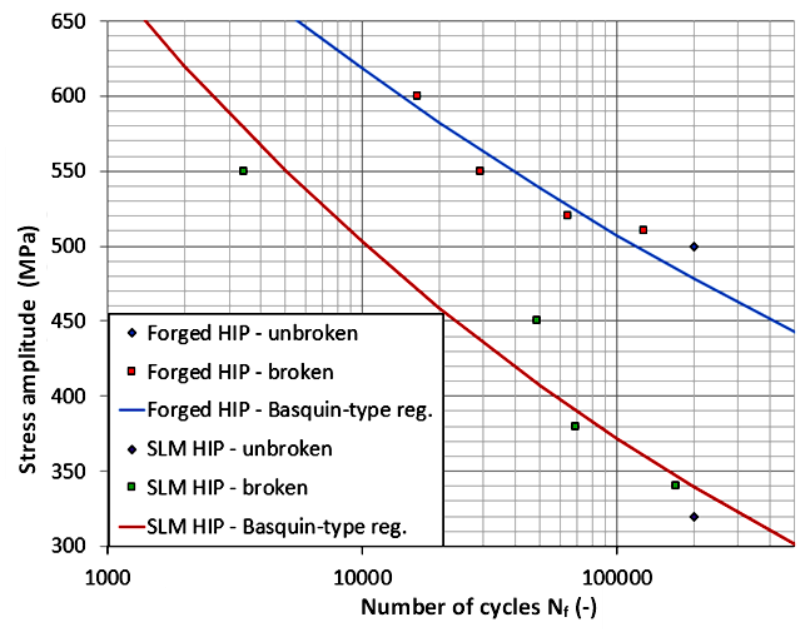

Figure 4 Comparison of $\mathrm{S}-\mathrm{N}$ curves for forged and SLM samples in annealed + HIPped condition

Table 2 Constants of Basquin approximation

\begin{tabular}{|c|c|c|}
\hline Specimens & $\boldsymbol{\sigma}_{\boldsymbol{f}}^{\prime}(\mathrm{MPa})$ & $\boldsymbol{b}(-)$ \\
\hline Forged specimens in as-received condition & $1.84 \mathrm{E}+30$ & 9.513 \\
\hline Forged specimens annealed + HIPped & $4.64 \mathrm{E}+36$ & 11.705 \\
\hline SLM specimens annealed + HIPped & $4.50 \mathrm{E}+24$ & 7.646 \\
\hline
\end{tabular}

\subsection{Microstructure}

Conventionally produced (forged) Ti6Al4V alloy shows a bimodal structure consisting of $\alpha+\beta$ phases, which consist of isolated primary a grains in a transformed $\beta$ matrix to very fine and intercrystalline needle-like $\alpha+\beta$ regions, as it is seen in Figure 5a. After the SR annealing at $735^{\circ} \mathrm{C}$ and HIPping at $920^{\circ} \mathrm{C}$ that is below $\beta$ transus $\left(980^{\circ} \mathrm{C}[10]\right)$ of the Ti6Al4V alloys the microstructure is formed of the equiaxed $\alpha$ and former $\beta$ grains transformed into needle-like $\alpha+\beta$ regions, see Figure $5 \mathbf{b}$. As-built microstructure produced by SLM process is characteristic by $\alpha^{\prime}$ martensitic phase and more or less of porosity (Figure 6a). During heat treatment + HIPping below the $\beta$ transus the martensitic structure transforms to very fine $\alpha+\beta$ phases mixture. Upon heating, $\alpha$ phase nucleates at the former $\beta$ grain boundaries and vanadium atoms are moving away from new $\alpha$ phase that favors lamellar $\beta$ phase forming. The grain boundary of the former $\beta$ phase with $\alpha$ grains can be seen in the center of the Figure $6 \mathrm{~b}$. For both types of samples HIPping at $920^{\circ} \mathrm{C}$ and $100 \mathrm{MPa}$ for $2 \mathrm{~h}$ leads to $\alpha+\beta$ lamellae grow and grain coarsening.

Fractography study revealed important differences in fracture features of the forged and SLM samples in annealed + HIPped condition. Unlike forged samples with typical fatigue failure (Figure 7a), the SLM samples was characteristic by more rugged surface with less distinct signs of fatigue. Conversely, the failure surfaces show the important effect of scanning strategy of SLM process as well as of defects and cracks as seen after low cycle fatigue (Figure $7 \mathbf{b}$ ), even if the microstructure was formed of very fine $\alpha+\beta$ (Figure $6 \mathbf{b}$ ). Despite the coarsen $\alpha+\beta$ microstructure (Figure $5 \mathbf{b}$ ) the fatigue fracture of the forged sample in annealed + HIPped condition after 127,361 cycles corresponds to the highest reversing stress of high cycle fatigue (Table 1). 

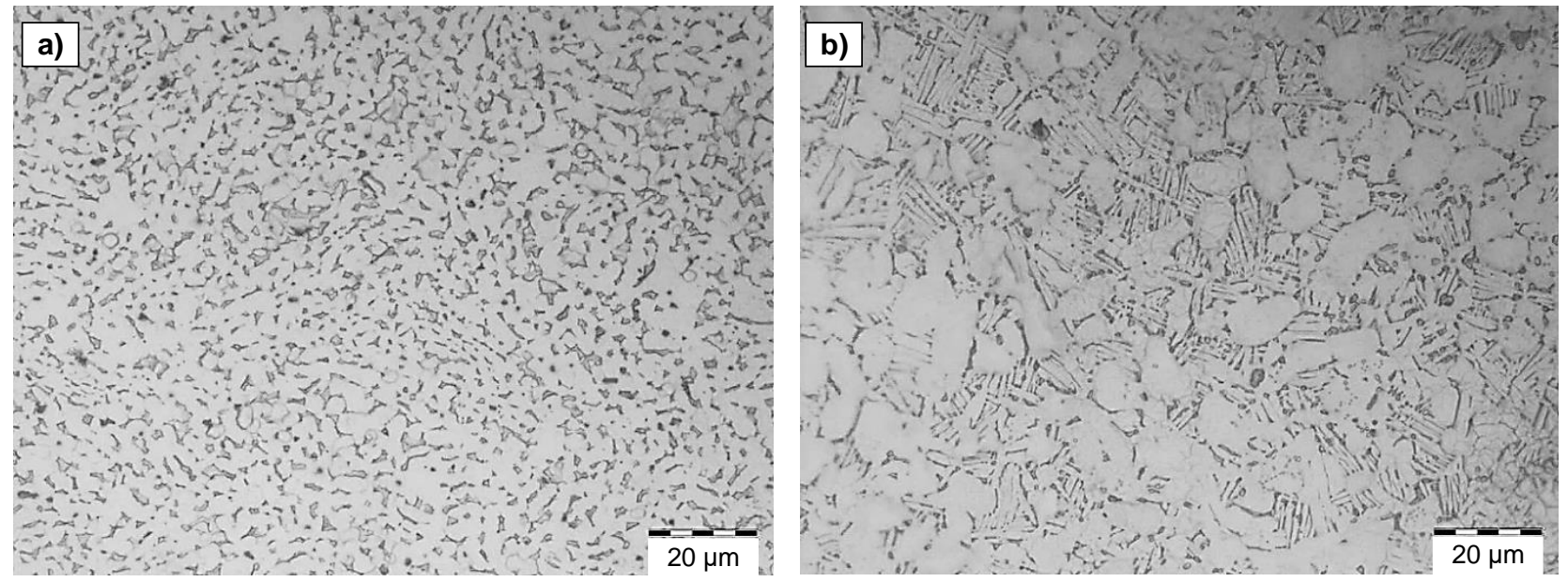

Figure 5 Microstructure of forged sample in a) as-received and b) annealed + HIPped condition
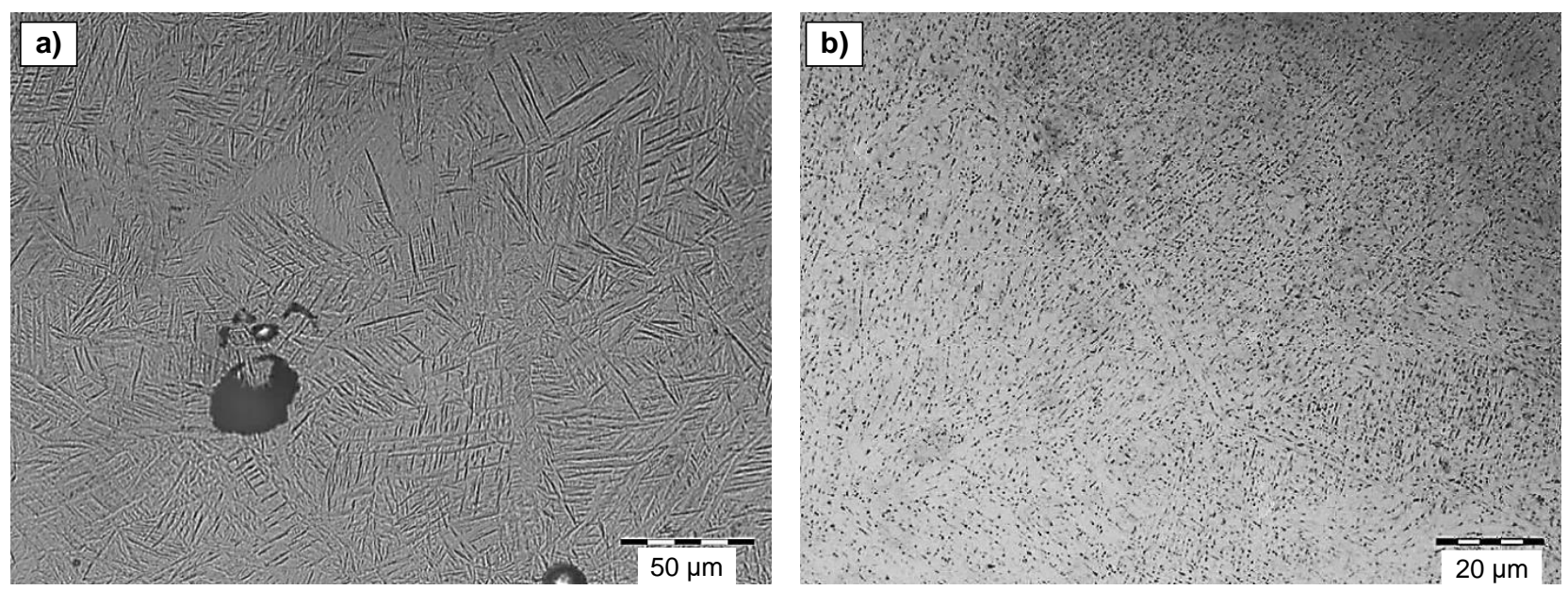

Figure 6 Microstructure of SLM specimen in a) as-built and b) annealed + HIPped condition
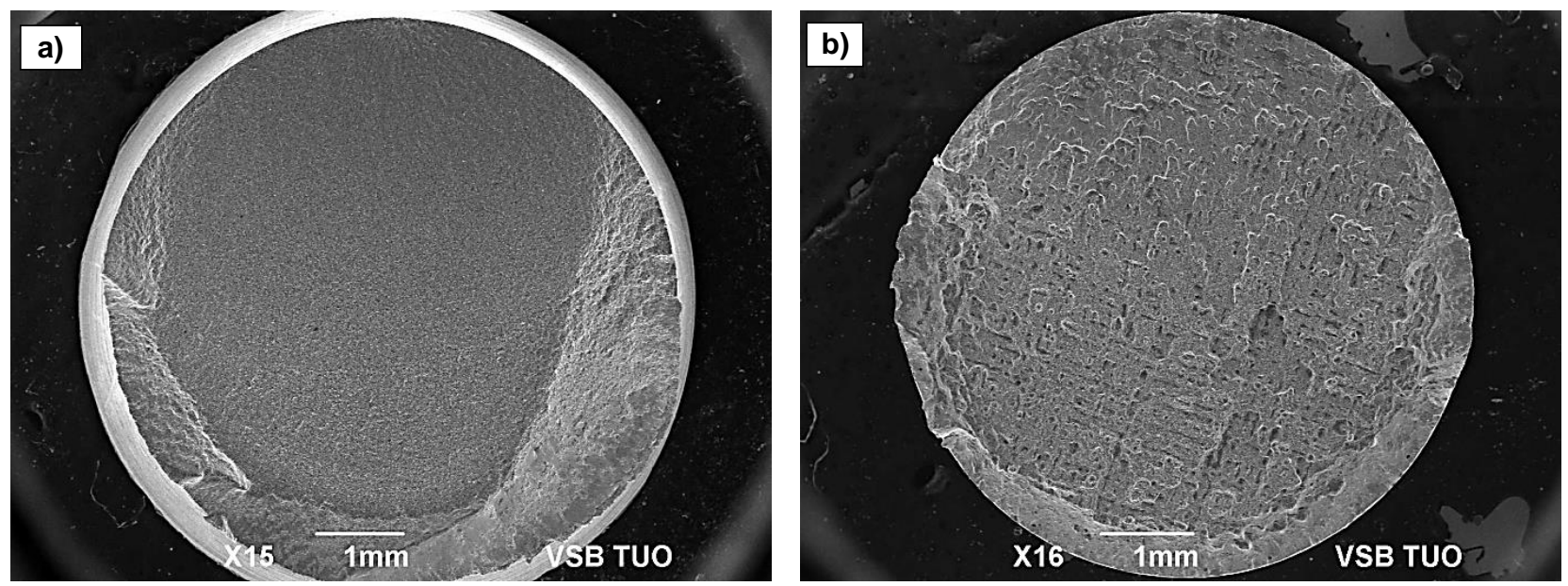

Figure 7 Fatigue surfaces of a) forged and b) SLM samples both in annealed + HIPped condition after 127,361 and 3,419 cycles, respectively 


\section{CONCLUSION}

The comparison of the microstructure features and fatigue behavior was made for the specimens of Ti6Al4V alloy prepared using selective laser melting technology or conventional way, i.e. by casting and forging. The forged samples were studied in both as-received and annealed + hot isostatic pressed conditions; the selective laser melted samples were tested after annealing + hot isostatic pressing. The forged specimens showed better fatigue properties at higher reversing stresses than the selective laser melted samples, that corresponds to defects formed during the powder-bed-based additive manufacturing process. Small differences in life-time were observed between both heat treatment conditions for the forged samples. Despite certain porosity, the samples prepared by selective laser melting showed high endurance limit of 200,000 cycles at $320 \mathrm{MPa}$. Comparing to the forged specimens in as-received or heat treated + hot isostatic pressed conditions, this reversing stress were lower by $26 \%$ or $36 \%$, respectively. Considering the defects and porosity presence the lower stress can be explained by crack initiation at these sites. The fatigue failure of the tested specimens prepared by selective laser melting showed more rough surfaces with less evident fatigues features unlike forged samples.

\section{ACKNOWLEDGEMENTS}

This work has been realized in the framework of the following projects: FV40306 "Development of new implants for the regulation of lower limb growth in a sterile design", SGS SP2021/41 "Specific research in metallurgical, material and processing engineering" and SGS SP2021/62 "Materials based on non-ferrous metals - preparation, procedures for improving their properties, areas of application and the possibility of recycling selected types of waste".

\section{REFERENCES}

[1] LOSERTOVÁ, M., KUBEŠ, V., DRÁPALA, J., DOSTÁLOVÁ, K., SEVOSTYANOV, M. A., DI COCCO, V., IACOVIELLO, F. Influence of microstructure on fracture feature of Ti6Al4V alloy prepared by 3D printing. IOP Conference Series: Materials Science and Engineering. [online]. 2020, vol. 726, Art. No. 012020. Available from: https://doi.org/10.1088/1757-899X/726/1/012020.

[2] NIINOMI, M. Mechanical biocompatibilities of titanium alloys for biomedical applications. Journal of the Mechanical Behavior of Biomedical Materials. 2008, vol. 1, no. 1, pp. 30-42.

[3] GEETHA, M., SINGH, A.K., ASOKAMANI, R., GOGIA, A.K. Ti based biomaterials, the ultimate choice for orthopaedic implants-a review. Progress in Materials Science. 2009, vol. 54, no. 3, pp. 397-425.

[4] THIJS, L., VERHAEGHE, F., CRAEGHS, T., VAN HUMBEECK, J., KRUTH, J.P. A study of the microstructural evolution during selective laser melting of Ti-6Al-4V. Acta Materialia. 2010, vol. 58, no. 9, pp. 3303-3312.

[5] OLAKANMI, E. O., COCHRANE, R. F., DALGARNO, K.W. A review on selective laser sintering/melting (SLS/SLM) of aluminium alloy powders: Processing, microstructure, and properties. Progress in Materials Science. 2015, vol. 74, pp. 401-477.

[6] WANG, Z., XIAO, Z., TSE, Y., HUANG, CH., ZHANG, W. Optimization of processing parameters and establishment of a relationship between microstructure and mechanical properties of SLM titanium alloy. Optics and Laser Technology. 2019, vol. 112, pp. 159-167.

[7] RANS, C., MICHIELSSEN, J., WALKER, M., WANG, W. Beyond the orthogonal: on the influence of build orientation on fatigue crack growth in SLM Ti-6Al-4V. International Journal of Fatigue. 2018, vol. 116, pp. 344-354.

[8] CHASTAND, V., QUAGEBEUR, P., MAIA, W., CHARKALUK, E. Comparative study of fatigue properties of Ti$6 \mathrm{Al}-4 \mathrm{~V}$ specimens built by electron beam melting (EBM) and selective laser melting (SLM). Materials Characterization. 2018, vol. 143, pp. 76-81. 
[9] PAPUGA, J., FOJTÍK, F. Multiaxial fatigue strength of common structural steel and the response of some estimation methods. International Journal of Fatigue. 2017, vol. 104, pp. 27-42.

[10] ASM Material Data Sheet. Titanium Ti-6Al-4V (Grade 5), Annealed. [online]. 2015. [viewed: 2015-08-05]. Available from: http://asm.matweb.com/search/SpecificMaterial.asp?bassnum=MTP641 